\title{
REDD+ and Participatory Processes in the Congo Basin Forests Countries: A Critical Reading of the Appropriation of the Free Prior Informed Consent
}

\author{
KENFACK Chrislain Eric
}

\begin{abstract}
The current global climate regime gives a great importance to the protection of forests, as a valuable opportunity for the salvation of our planet from climate catastrophes. This effort is manifested through the different attempts to put in place suitable climate protection policies and projects in the context of the REDD mechanism. Unfortunately, despite all the actions of States as well as non-state actors in building the REDD mechanism at the international level, their impacts seem to be limited. In this article, based on the limited circulation of information and implication of the local communities and indigenous people in the Congo Basin region, I argue that only the proper implementation of the Free Prior Informed Consent can guarantee the success of REDD policies and projects. Such implementation, apart from building a sense of belonging and sympathy of local people, contribute to the protection of their fundamental right to participation, access to resources and protection of their resources and cultures among others.
\end{abstract}

Keywords: Congo Basin Forests, Free Prior Informed Consent, REDD, participation, Indigenous people rights

\section{INTRODUCTION}

The ongoing global climate debates and negotiations give a great importance to the forests as an additional chance to save our planet from irreversible climate catastrophes and damages. This situation is justified by the fact that, through the change in the use of lands in general and specifically through tropical deforestation, the forest sector is responsible of $1 / 5$ of the global emissions of carbon dioxide (Kaninen et al., 2009). Controlling this huge source of pollution will therefore be of great relevance for the global fight against climate change. It is in this context that the REDD mechanism (Reduction of emissions due to deforestation and forests degradation) was framed, with the aim of providing incentives to forest countries so that they can preserve their forests and thus contribute to the global common fight. Within the framework of this mechanism a great importance is given to the participation of indigenous people through the Free Prior Informed Consent (thereafter FPIC) principle. According to this principle, for any project to be validated under REDD, it has to obtain the consent of the indigenous people and forest communities living in and around the area where it is supposed to be implemented, and such consent should be free from any coercion and manipulation, and be duly enlightened by a good knowledge of the positive and negative effects of the project.

The Congo Basin forest, as the second biggest tropical forest in the world after the Amazonian forest, is greatly concerned by this mechanism. Equally, the countries of the sub-region are highly active and involved in the global REDD debates and activities. This research aims at investigating the implementation of the FPIC as a participatory dynamic under the REDD mechanism in the Congo Basin forest countries. In order to better investigate and understand the reality, I will base my analysis on the fieldwork that we carried out under the framework of the COBAM project. The work will be organised around four main points, namely:

- The presentation of the research methodology

- The analysis of the REDD mechanism and the FPIC based on the existing literature

- The presentation of the state of information, knowledge and practice of the REDD in the Congo Basin based on the field work results

- The analysis of the limits of the implementation of the FPIC in the sub-region, followed by some perspectives and propositions. 


\section{RESEARCH METHODOLOGY}

The research methodology used for this paper was made up of two different components, namely the literature review to investigate what has been written and said on REDD in general and the FPIC in particular, and the fieldwork to collect the necessary empirical materials.

\subsection{Literature Review}

It is important to note that there is a huge literature on the emerging REDD+ mechanism, but most of the publications are oriented toward technical issues related to the financial, the MonitoringReporting- Verification (MRV), the environmental and social safeguards, and the benefits sharing. To a certain extend the FPIC seems to be a bit neglected. The few publications available on the topic are mostly related to the practices of this principle in specific contexts, namely in South America and Asia. Because of that limited literature on the FPIC, and practically the non-existence of such publication in the specific case of the Congo Basin Forest, my current work will be based on the few exploratory works published with a special focus on the participation of local communities on environmental matters or the FPIC by authors such as Takacs (2014) who, in his text, insists on the PFIC as an instrument of participatory democracy and protection of the rights and resources of indigenous people in the context of REDD+, Kant (2010), who warns about the possible misuses of the FPIC to legitimize top-down REDD policies without really involving the indigenous people, Tamang (2005) who stresses on the legal dimensions and possible ways of integrating the FPIC into national legal instruments, and the UN-REDD directives on the FPIC set in two important documents, namely the Guidelines on Free, Prior and Informed Consent (2013), And the Legal Companion to the UN-REDD Programme Guidelines on Free, Prior and Informed Consent (FPIC): International Law and Jurisprudence Affirming the Requirement of FPIC (2013).

\subsection{Fieldwork and Data Analysis}

The empirical materials used in this work to evaluate the level of appropriation of the FPIC in the Congo Basin forests Countries come from a fieldwork ${ }^{i}$ that we carried out during the months of October and November 2012 related to the circulation of information and knowledge on Adaptation and REDD+ in the Congo Basin countries. Even though the fieldwork was not specifically focused on the FPIC, a great importance was attached to this principle, since it is one of the key concepts of the REDD+ mechanism.

During this fieldwork a semi-structured questionnaire and an interview guide were used, and the interviewees approached were from government officials, national and international NGOs, national and international research institutes, diplomatic missions, funding institutions and Medias among others. The semi-structured questionnaire was given to the interviewees some days before the interviews, and during the interviews the interview a guide was equally used by the interviewers. Respondents were selected on the basis of their activities related to the fight against climate change and the production/dissemination of information related to climate change in general or the adaptation and REDD+ key concepts in particular. The FPIC is one of those key concepts. The focus on the circulation of information and knowledge on REDD concepts in general and the FPIC in particular is quite important and of great relevance for us, as it is a pre-requisite for the implementation of any given project. In fact, we cannot properly implement a mechanism if we do not have clear information and appropriation of the said mechanism, and the way we implement projects depends on the level of understanding we have of their implications. In other words, the availability and circulation of information on a given project help to better understand it and, in return, the more people understand a project, they better they can participate in its implementation and make it successful.

The analysis of the data collected focuses both on the quantity of information circulated and on their quality. This aims both at ensuring their availability, and their compliance with the general and global understanding of the principles concerned. The fieldwork was carried out in Cameroon (39 organizations), in Gabon (33 organizations), in Congo (28 organizations) and in the Democratic Republic of Congo (16 organizations). These countries were chosen not only for their position at the heart of the Congo Basin forests, but also because of their involvement in the climate change negotiations and fight, and their constant efforts in putting in place viable forest policies. 
REDD+ and Participatory Processes in the Congo Basin Forests Countries: A Critical Reading of the Appropriation of the Free Prior Informed Consent

\subsection{Limits of the Methodology}

Even though they cannot hinder the relevance of the research, it is worth noticing that some difficulties encountered rendered it more complicated. The relatively limited literature production on the FPIC in the context of REDD made the construction of the conceptual framework of this paper quite complicated; most published documents are either directives or reports from some International Organizations.

On the other hand, the object of the research was quite huge, and the time limited. In fact, the fieldwork did not only focus on the FPIC, but on more concepts, and the number of actors encountered in a very limited time was huge. Another important limit was related to the omission of representatives of Indigenous people and forest community among the interviewees. In fact, giving the importance of these categories of actors in the context of the REDD mechanism, their omission is an element that can lead to the partial understanding of the reality.

\section{FPIC AND THE REDD MECHANISM IN WRITTEN LITERATURE}

\subsection{Birth and Evolution of the REDD Mechanism}

Limiting the emissions resulting for the forest sector is one of the key priorities of the international community facing the challenges of global warming. And this is the reason why a great importance is being given to forests at the present moment in global negotiations. Such importance is mainly explained by the fact that the forest sector alone is responsible for the emission of approximately $20 \%$ of the world Greenhouse Gases emissions (Kaninnen et al., 2009), and it is in this context that we can situate the development of the REDD mechanism. Launched in 2005 in Montreal at the 11th Conference of Parties (COP) with the aim of reducing the emissions due to deforestation in the developing Countries (RED), the mechanism incorporated the forest degradation dimension in 2007 and became Reduction of emissions due to deforestation and forest degradation in developing Countries (REDD) in Bali at the COP 13, under the initiative of Norway. In 2008 in Poznan and 2009 in Copenhagen respectively, other variables will be added to the mechanism, symbolized by the sign "+", and we will end up having REDD+. The "+" in the context referring to additional aspects related to the forest governance, the conservation of forest carbon stocks, the sustainable management of forests, the enhancement of the forest capacity in stocking the carbon through afforestationreforestation, and the rehabilitation of lands (CIFOR, 2009). The diagram below indicates in a much summarized way the historical evolution of the REDD mechanism within the United Nations Framework Convention on Climate Change (UNFCCC).

\section{REDD+ evolution under the UNFCCC}

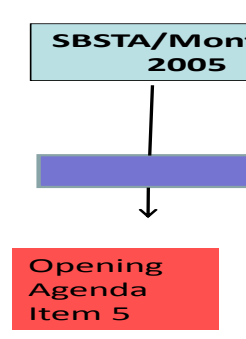

RED

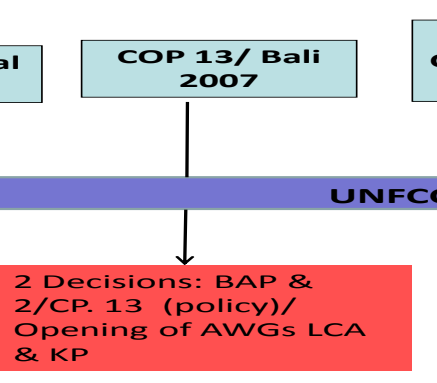

RED D

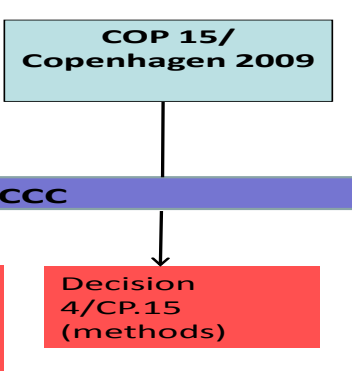

REDD+

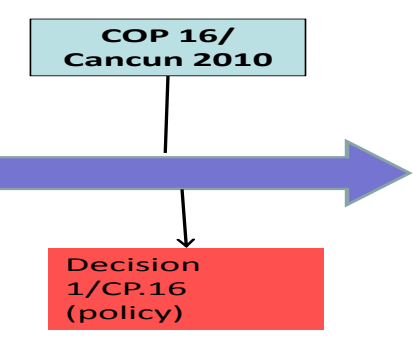

REDD+

Source.Clea Paz-Rivera and UN-REDD Secretariat (2011)

In short, we can say that the objective of the REDD mechanism is simple: provide "positive incentives", interpreted by many as financial remuneration from rich countries to developing ones, in exchange of measurable reduction of forest emissions (Angelsen et al., 2013). This payment for the preservation of forests as carbon sinks to fight against global warming may happen on a project-byproject basis, where a developer contracts with landowners to preserve or reforest a discrete area of land, and sells the carbon thus sequestered. Or, it may operate on a broader scale, i.e., a nation, state, or province where REDD+ funding are used to reduce deforestation or promote reforestation in a wide 
geographic area, resulting in greater stored carbon (Takacs, 2014). REDD is put in place in three main phases: the planning phase during which national strategies are elaborated and people's capacity are built to better carry out the tasks, the preparation phase during which the various managing structures are created and start functioning, and the implementation phase during which the REDD projects are fully executed and the payment received and shared. Nevertheless, even though the aim of the mechanism seems easy to express, its implementation is subjected to more complex issues that have not yet found solutions both at the global, national and sub-national levels. These issues are mostly related to the financial aspects, the Monitoring- Reporting- Verification of the effectiveness, the efficacy and efficiency of REDD projects, the socio-environmental safeguards, and the Free Prior Informed Consent (FPIC), among others. This research mainly focuses on the FPIC as a participatory dynamic.

\subsection{FPICin REDD: An Indigenous Rights-Based Approach}

The FPIC is fundamental as a participatory mechanism for the indigenous people in particular and local communities in general. In fact, decision making processes affecting the vital resources of local communities should always involve them. According to principle 10 of the 1992 United Nations Conference on Environment and Development known as the Rio conference:

Environmental issues are best handled with participation of all concerned citizens, at the relevant level. At the national level, each individual shall have appropriate access to information concerning the environment that is held by public authorities, including information on hazardous materials and activities in their communities, and the opportunity to participate in decision-making processes. States shall facilitate and encourage public awareness and participation by making information widely available. Effective access to judicial and administrative proceedings, including redress and remedy, shall be provided.

From the above declaration there are basically three environmental democracy rights to be respected, namely: the right to participate in environmental decision making, the right for citizens affected by environmental decisions to receive pertinent information, the right to access judicial and administrative proceedings. The FPIC to be given by indigenous and other forest dependent populations, and possibly by all local citizens when decisions about environmental resources vital to their lives are made is to be situated and understood in the context of those environmental rights, as a continuation of those enunciated by the Rio declaration (Takacs, 2014). The aim of this human rightsbased approach, according to Hunter (2009) is to inform a reprioritization of policy responses to climate change away from one focused on carbon accounting and toward one that considers more fully principles of equity, fairness, and impact on the most vulnerable. In this context, the FPIC is not just a simple formality to be fulfilled, but a human right requirement. In fact, the principle of consultation and free consent constitute a fundamental standard for the safeguard and the exercise of the property rights, the right to participation, the non-discrimination, the right to self-determination, the cultural rights, the right to food and health, and the right to freedom of expression of the indigenous people.

On the other hand, even though the FPIC was developed before the REDD mechanism, it has become one of its key components. For a project to be considered within the REDD framework, get approved and be funded, it has to receive the FPIC of the "benefiting community". The UN-REDD program supports the national processes and promotes the deep and full participation of all the stakeholders and, above all that of the indigenous people and other forest dependent communities, in the conception and implementation of the national REDD+ (ONU-REDD, 2013a). The participation of local populations in the decision making processes concerning the use of forests and lands has the potential to reduce the risks and increase the benefits related to REDD+ investments; this comes from the fact that indigenous people live in and around the majority of the tropical forests around the world, and have strong ancestral and customary links with the forests. Taking into consideration those links is an unavoidable task for the sustainable management and use of the forests (ONU-REDD, 2013b). In the context of REDD+, the FPIC will help in protecting the rights of indigenous people against the adverse effects of the change in the use of lands and forests. If we refer to the words of the InterAmerican Commission on Human Rights, cited by Tamang (2005), special measures to ensure recognition of the particular and collective interest that indigenous people have in the occupation and use of their traditional lands and resources, and their right not to be deprived of this interest except with fully informed consent, have to be considered in any REDD project. This 
can be done through the establishment of fora, information and participatory procedures whereby local and indigenous communities may have the option to accept or oppose proposed projects that may impact their community and resources (SCBD, 2004; UN-REDD, 2013a; UN-REDD, 2013b). In this context, the process does not merely aims at consulting the indigenous people, but at obtaining their consent. The importance of insisting on consent rather than consultation lies in the basic difference between the two approaches, as pointed out by Maharjan et al. (2012): Consent is the result of an independent and collective decision-making process to a certain proposal or action. On the other hand, consultation is a mechanism as a democratic right for expressing and exchanging views and opinions on a certain issue, proposal or action to influence its outcome or final decision. The FPIC in the context of REDD+ does not merely aims at giving an influential role to indigenous people with regard to the outcomes of the decision, but above all it aims at providing them with the tools, and letting them be the full actors of the final outcomes. It is with this understanding that, in the next section, I will analyse the implementation of the FPIC in the REDD in the Congo Basin forests countries.

\section{FPIC AND REDD MEChANISM IN THE CONGo BASIN Forests COUNTRIES: WhERE ARE WE?}

\subsection{Circulation of Information and Knowledge on the FPIC in the Congo Basin Forest Countries}

Afterthe Amazonian forest, the Congo Basin forest is considered to be the second lung of the planet. That is why it is so important in the context of REDD, that has as a goal saving the forests as sinks for the sequestration of carbon. But if the Congo Basin is considered of such importance in this context, how far have the sub-region countries gone as far as the appropriation of the REDD concepts is concerned? This section will, based on the results of our fieldwork, present the inventory of the circulation of information and knowledge on the REDD in the sub-region, with a specific focus on the FPIC. This is of great importance, if we consider that understanding a phenomenon is an unavoidable pre-requisite for its proper implementation. In fact, the level of circulation of the information and knowledge reveals the level of willingness and readiness to implement a given practice; we cannot implement what we do not know or have never heard about. That is the reason why, assessing the level of information and knowledge circulation among the different stakeholders in the Congo Basin is of fundamental importance in detecting the shortcomings of the practice. (Lee et al. 2001) In fact, the results of some recent researches demonstrate that generally, in the sub-region, policy makers, civil society organizations and local communities lack the appropriate information and knowledge. That is one of the reasons why they cannot put in place suitable environmental policies and projects, or effectively participate in the decision making processes (Gapia and Bele, 2012; Nguema and Pavageau, 2012; Pongui and Kenfack, 2012; Kengoum and Tiani, 2013). Based on those conclusions, this paper seeks to investigate in a specific way the case of the FPIC in the sub-region.

In fact, according to the results of our survey ${ }^{\mathrm{ii}}$ an average of $68.97 \%$ of the Organizations encountered work on REDD topics in general and, when it comes to specific countries cases, $93.75 \%$ do work on REDD in the DRC, $87.18 \%$ in Cameroon, $60.42 \%$ in Congo and $42.2 \%$ in Gabon. This enthusiasm of the countries of the sub-region related to REDD issues can be explained by the huge financial advantages that being a REDD country entails. In fact the same enthusiasm is not manifested for other aspects of the mitigation processes such as the payment for environmental services (34.48\%) and the clean development mechanism (33.62\%) among others, which do not have the same level of financial incentives. Also working on the REDD mechanism, the organizations at the sub-regional and national levels do not attach the same importance to all the key issues related to the mechanism and, in general, the FPIC seems to be less considered, even though all do recognize its relevance and importance.

Generally, 37.07\% of the organizations interviewed are concerned by the FPIC in their research activities or information sharing in the Congo Basin forests countries. When we consider specific cases, we realize that, in Cameroon, only $30.77 \%$ of the respondents (these are mostly international research organisations, national and international NGOs, networks of organisations, intergovernmental organisations and bilateral technical partners) share information on this matter with the State, and $17.95 \%$ with local communities. In general, organisations do not share much information on FPIC among themselves. In Gabon, 27.27\% of the organizations work on the FPIC, 
but paradoxically, only $10 \%$ do share information among themselves, and national NGOs are those more active in this respect. In Congo, the situation is quasi similar: information and knowledge on the FPIC is mainly circulated by national NGOs, and they exchange with ministries, local communities, other national NGOs. In the Democratic Republic of Congo (DRC), very few organisations share information on the FPIC; in fact, while half of the organizations recognize the importance of the mechanism, only $6.25 \%$ share information and knowledge concerning it.

As far as channels are concerned, one can realize that in general $30.17 \%$ of the organizations use the workshops and seminars to share information on the FPIC, $6.03 \%$ use scientific publications, $4.31 \%$ use the television, $4.31 \%$ use the radio, and $2.59 \%$ the Internet. The main channels used for communication seem in most cases inadequate, if we take into consideration the fact that the first people concerned with the FPIC are the local communities in general and the Indigenous people in particular. In fact, these categories of the population do not have easy access to the channels used, and are not equipped with the materials and tools necessary for their usage. The internet coverage is very low in the sub-region and, even in the main cities very few people do have access to the Internet. When the situation comes to the villages where most indigenous people are found, there is practically no Internet coverage, and we can ask ourselves how can they be expected to use a tool they cannot have access to, for their information. The use of seminars and workshops is reserved for the same categories of officials, experts and high profile participants, and then poses the problem of representativeness of the indigenous and local communities. The radio and television coverage is also very low and is not affordable by most people because of the lack of electricity supply in most villages, the fact that most people are peasants and do not always have the time to follow television and radio programmes, and the language used for most programmes are beyond their reach. This situation equally participates in limiting their access to the information and knowledge on the FPIC.

From the above statistics, I have demonstrated that there is a relatively limited circulation of information on the FPIC among the different stakeholders at the national and sub-regional levels. What about the implementation of the mechanism? The next paragraph will address this topic.

\subsection{Practice of the FPIC in the Congo Basin Forest Countries}

The approval of the Readiness Proposal Plans (RPP) of Cameroon, Congo and the DRC is an indication that those countries have already implemented most of the procedures, rules and practices of the REDD mechanism. Among those procedures, one of the key elements is the FPIC, that has to be respected before, during and after the implementation of REDD projects. Unfortunately, the reality shows that, in those countries, the procedure was not fully applied, and the FPIC was not carried out prior to the conception of Readiness Proposal Plans (RPP) as it should be. In Cameroon for example the government as well as the private sector and the civil society did not and still do not show a specific interest to the FPIC. During the research, a government official from the ministry of the environment of Cameroon clearly indicated that trees belong to the government and not to local communities [...] you cannot expect us to ask to Pygmies iii to give their consent! This statement demonstrates the reality in the country's policy, where local populations are excluded from decision making processes. If the Pygmies who have the forest as their immediate living environment are not expected to give their consent, it is a clear indication that the FPIC has not been carried out as indicated by international procedures and standards. The situation is quasi similar in the other countries of the sub-region. Nevertheless, it is worth noticing that in the specific case of Congo the FPIC norms were widely used in the context of mining and forest policies decision-making processes (Mahanty and McDermott, 2013). Unfortunately, it did not continue in the context of the REDD mechanism. In this same context, it is important to note that there is a growing number of national and international NGOs which are constantly pleading for the land tenure and rights to resources of the local communities, with the help of some International Organisations and networks of Organisations, even though such actions cannot replace the FPIC. In fact, there exist no general debate on the role of governments, NGOs, financial institutions and market-based actors in initiating and applying the FPIC for social equity outcomes (Mahanty and McDermott, 2013).

\section{FPIC In REDD IN THE CONgo BASIN Forest Countries: LiMits AND PERSPECTIVES}

\subsection{Limits of the Practice of the FPIC in the Congo Basin Countries}

The first problem faced as far as the implementation of the FPIC is concerned in the Congo Basin is related to limited amount of information circulating at the regional and national levels on the 
procedures, and the low involvement of key actors. In general, from the statistics, we can see that States and local communities, at the level of the Congo Basin forest, still play a marginal role in the production and dissemination of information and knowledge. In fact States are there to regulate development activities, the follow-up and implementation of sectorial policies (Burton and Mustelin, 2013), the local communities are the first beneficiaries of the projects and their self-identification with projects is fundamental for the success of those projects. This marginal implication is therefore a serious point of concern given the important role these two categories of actors are supposed to play in the conception and the implementation of REDD in general and the FPIC in particular. It is important to mention that this marginal role is partly related to the non-recognition of the customary rights of the indigenous people to own the forests and the lands (Edwards et al., 2012). The declaration of the Cameroon government official we quoted before demonstrates this general denial of the rights of the indigenous people; In Cameroon for example, just as in the other countries of the subregion all the lands and trees belong to the States, and the political leaders think there is no need for proper and deeper inclusive participation of the indigenous and local communities in the strategic decision-making processes (Puntenney, 2009; Aprile, 2013). On the side of the local communities and indigenous people, the limited participation is routed in the fear that has been installed by the administration. In fact, for the implementation of forest and land tenure laws, which were in most cases voted and imposed from a top-down perspective, administrations used and continue to use coercive powers, and this created and continues to maintain a certain fear among the indigenous and local communities ${ }^{\text {iv }}$.

Another point of concern in the Congo Basin is the problem of representativeness of the indigenous people and the local communities. In fact, because of their ignorance of the norms, laws and procedures set by central and local authorities concerning the forests and lands, they end up being represented by their leaders and elites who are more incline to defend their personal interests than those of the community. In fact, one should not assume that because a particular person 'represents' a specific group or institution, that he or she necessarily acts in the interests or on behalf of his/her fellows. The link between representatives and constituencies (with their differentiated memberships) must be empirically established, not taken for granted (Long 2001, quoted by Aprile, 2013). In this situation, the populations often feel that decisions are taken from a top-down perspective, and local leaders and elites are put into contribution, and corrupted to serve their own interests and maintain those of the administration. Taking advantage of the low understanding of procedures and laws by forest people communities, they often pretend to act on their behalf. If we consider the fact that the FPIC is based on principles of self-determination, and is understood as the collective right of indigenous peoples and local communities to negotiate the terms of externally imposed policies, programs, and projects that directly affect their livelihoods and wellbeing (Edwards et al., 2012), we can take this problem of representativeness as a big threat for FPIC in the sub-region.

\subsection{Perspectives for a Better Appropriation and implementation of the FPIC in the Congo Basin Countries}

The need for a clear and organized communication and formation mechanism has to be greatly valued and solved. The implementation of the FPIC demands a high level of preparation and understanding. For this reason it is important to take time to inform, form and empower the indigenous people in particular and the forest communities in general; they need tools to be able to fully participate in the decision making processes and give or refuse their consent. In this context, time and resources need to be allocated for better preparation (Fobissie et al., 2012; Alemagri et al, 2014), and they have to be empowered not only on the REDD projects, but also on the proper meaning and finality of the FPIC. In fact, they have to clearly understand that, under the REDD mechanism the concept "free" refers to the complete absence of coercion or manipulation, "prior" means they ought to have enough time to form a collective opinion and the word "informed" implies that they have been duly informed about the locality, size, reversibility, scope, duration and the purpose of the project, along with a honest assessment of socio-economic, cultural and environmental impacts, and the risk and benefits that are likely to accrue to the people (UN-REDD, 2009; Kant, 2010). This awareness can both be raised through an organized and lasting formation, and the delivery of proper and right information to the indigenous and forest communities, not forgetting the direct participation in decision making fora themselves, as this will as well help them order to learn by doing. (Pateman, 2012) Both the 
empowerment and the implementation of the process have to be based on strategies that take into account the gender balance, the linguistic disparity and literacy levels (Lewis, 2012; Alemagri et al, 2014) on one side and, on the other side try to reconcile gender and social division to be more inclusive.

Other important feature is the creation of permanent and reliable dialogue mechanisms among the decision-makers, the research institutions and the indigenous people. In fact, from the findings, it is clear that such mechanism does not exist, and where it has been created, it is not yet operational. There is a lot of information available across the various research organisations in the sub-region, but those information remain relatively kept within the organisations, and therefore cannot be used to foster the FPIC. Knowledge sharing, and its translation into policy relevant material is very important not only for the credibility and accountability of science as Jasanoff (2010) points out, but above all, it is important as it makes science more usable and useful for the society. That is why, at the level of the Congo Basin forest countries, it is more than ever important to establish a clear science-policy dialogue framework and mechanism, so as to turn the huge scientific production into a usable knowledge at the local levels (Lemos and Morehouse, 2005; National Research Council, 2009a; National Research Council, 2009b; Weiss, 1978). In the same line, an important place has to be given to the constant dialogue with indigenous people in particular and local communities in general. In fact, they can provide specialized indigenous knowledge and skills on the ecological and socioeconomic environment (Naguib, 2013), since their worldview of the landscape is not viewed in pieces nor separated between forests, wildlife, rivers, etc. For them the relationship with the land is experienced in a very holistic way, and nature cannot be understood independently from what they contain. Because of that Unitarian view of nature, they end up creating a very harmonious and respectful relationship not only with nature as a whole but also with the forest in particular. (Wyatt, 2008) Such harmonious worldview is very important for the success of environmental protection projects in general, and the REDD in particular. That is the reason why, in this regard, the dialogue with indigenous people will help in capitalising and using this local knowledge in the construction of the usable science in the REDD framework.

\section{Conclusion}

In conclusion I can state that the implementation of the FPIC does not only secure the participation of the indigenous people in the decision making processes, and the protection of their rights in the context of the REDD mechanism, but also, it gives them the possibility of accepting or rejecting any project that presents certain threats for their lives and their resources. More to that, it create a good sense of self-identification with the projects and guarantees their success; in fact, when people fully participate in the elaboration of a project, there are great chances that they will involve better in its implementation and make its success more sustainable, effective and efficient (Irvin and Stansbury, 2004)

Unfortunately, in the Congo Basin forest Countries, information and knowledge do not circulate much about the FPIC, and it is not really implemented by the countries of the sub-region, even though those countries have already submitted their RPP and are fully considered as REDD countries within the UN-REDD framework. This situation comes as a result of the non-recognition of the rights of the indigenous people and their low level of formal education coupled with the non-recognition of their local knowledge by decision-makers on one side, and the other side, the lack of proper representativeness in the decision making. To solve this situation and guarantee a better implementation of the FPIC in the REDD in the sub-region, it is necessary to proceed to a long term formation and empowerment of all the stakeholders, and to establish permanent structures and mechanisms of information, communication and dialogue with indigenous people in the Congo Basin forests; that is the only way we can guarantee their effective participation, the protection of their rights and their cultures, and the success of REDD projects in their lands and forests.

\section{REFERENCES}

[1] Alemagi D., Minang P. A., Feudjio M. and Duguma L. 2014. "REDD + readiness process in Cameroon: an analysis of multi-stakeholder perspectives." Climate Policy.http:// dx.doi.org /10.1080/14693062.2014.905439

[2] Angelsen, A., Brockhaus, M., Sunderlin, W.D. et Verchot, L.V. (éd.). 2013. Analyse de la REDD+: Les enjeux et les choix. Centre for International ForestryResearch (CIFOR). Bogor 
REDD+ and Participatory Processes in the Congo Basin Forests Countries: A Critical Reading of the Appropriation of the Free Prior Informed Consent

[3] Aprile A. M. 2013. FPIC and UN-REDD in Paraguay.Reprosentralen. University of Oslo. http://www.duo.uio.no/

[4] CIFOR. 2009. REDD tout simplement: Guide sur les forêts, le changement climatique et REDD. Centre for International ForestryResearch (CIFOR). Bogor

[5] Edwards K., Triraganon R., Silori C. and Stephenso J. 2012. Putting Free, Prior, and Informed Consent into Practice in REDD+ Initiatives. A Training Manual. RECOFTC, IGES and Norad, Bangkok, Thailand.

[6] Fobissie B. K., Essomba E. P., Sonne N., Ndobe S. N., and Retana V. (2012). Social safeguards and the rights of indigenous peoples in the REDD+ process in Cameroon: Lessons from experiences in natural resources management (Technical Report). Yaounde: The Worldwide Fund for Nature in Partnership with the Centre for Environment and Development.

[7] Gapia M. and Bele Y. 2012. Adaptation et atténuation en République centrafricaine : Acteurs et processus politiques. Document de travail 100. CIFOR. Bogor. Indonésie.

[8] Hunter D. 2009. "Human Rights Implications for Climate Change Negotiations." Oregon Review of International Law $11: 331-358$

[9] Irvin R. A. and Stansbury J. 2004. "Citizen Participation in Decision Making: Is it worth the effort?" Public Administration Review 64: 1

[10] Jasanoff S. 2010. "Testing Time for Climate Science" ScienceVol 328. www.sciencemag.org

[11] Kanninen M., Murdiyarso D., Seymour F., Angelsen A., Wunder S. and German. L. 2007. Do trees grow on money?: the implications of deforestation research for policies to promote REDD. Centre for International Forestry Research (CIFOR). Bogor

[12] Kant P. 2010. Avoiding Possible Misuse of FPIC in REDD. IGREG Working Paper. IGREC 17: 2010. Institute of Green Economy. New Delhi

[13] Lemos M.C., Morehouse B., 2005. "The co-production of science and policy in integrated climate assessments". Global Environmental Change 15, 57- 68.

[14] Lewis J. 2012. "How to implement free, prior informed consent". Participatory Learning and Action. 65, 175-178

[15] Long N. 2001. Development Sociology: actor perspectives. Routledge. London

[16] Mahanty S. and Mcdermott C. L. 2013. How does 'Free, Prior and Informed Consent' (FPIC) impact social equity? Lessons from mining and forestry and their implications for REDD+. Land Use Policy, 35, 406-416.

[17] Maharjan S. K., Carling J., and Sherpa L. N. 2012. Training manual on free, prior and informed consent (FPIC) in REDD+ for indigenous peoples. Asia Indigenous Peoples Pact (AIPP) and International Work Group for Indigenous Affairs (IWGIA). AIPP Printing Press Co., Ltd. Chiang Mai. Thailand,

[18] Naguib S. A. 2013. "Museums, Diasporas and the Sustainability of Intangible Cultural Heritage" Sustainability 2013, 5, 2178-2190. www.mdpi.com/journal/sustainability

[19] National Research Council. 2009a. Informing Decisions in a Changing Climate-Panel on Strategies and Methods for Climate-related Decision Support. National Research Council. Washington DC.

[20] National Research Council. 2009b. Restructuring Federal Climate Research to Meet the Challenges of Climate Change. National Research Council. Washington DC.

[21] Nguema J. and Pavageau C. 2012. Adaptation et atténuation en Guinée équatoriale: acteurs et processus politiques.Document de Travail 98. CIFOR. Bogor. Indonésie.

[22] Pateman C. 2012. Participatory democracy revisited. Perspectives on Politics. Volume, 10. Issue, 01. PP. 7-19

[23] Paz-Rivera C. and UN-REDD Secrétariat 2011. «REDD+ negotiations and key milestones from Cancun to Durban. » www.un-redd.org

[24] Pongui B. S. and Kenfack C. E. 2012. Adaptation et atténuation en République du Congo: Acteurs et processus politiques. Document de travail 99, CIFOR, Bogor, Indonésie

[25] Puntenney P. J. 2009. "Where Managerial and Scientific Knowledge Meet Sociocultural Systems: Local Realities, Global Responsibilities". In Anthropology \& Climate Change. Eds. Susan A. Crate and Mark Nuttall. Left Coast Press, Inc. Walnut Creek California. 
[26] Secretariat of the Convention on Biological Diversity (SCBD). 2004.Akwe: Kon Voluntary Guidelines for the Conduct of Cultural, Environmental and Social Assessments Regarding Developments Proposed to Take Place on, or which are likely to Impact on, Sacred Sites and on Lands and Waters Traditionally Occupied or used by Indigenous and Local Communities. Adopted at COP 7 in 2004. SCBD. Montreal

[27] Takacs D. 2014. "Environmental Democracy and forest carbon(REDD+). Environmental Law 44:71. http://ssrn.com/abstract=2424286

[28] Tamang P. 2005. "An Overview of the Principle of Free, Prior and Informed Consent and Indigenous Peoples in International and Domestic Law and Practices." Paper Presented at the Workshop on Free, Prior and Informed Consent and Indigenous Peoples, organized by the Secretariat of UNPFII, 17-19 January 2005,UN Headquarter, New York, USA

[29] Tchatchou B., Chia E. L., Sufo-Kankeu R., Pérez-Terán A. S., Tiani A. M. , Sonwa D. J., Kengoum F., Locatelli B., Mekou Y. B., Munoh A. et Kenfack C. E. 2015. Changement climatique dans le Bassin du Congo: Informations et connaissances échangées entre les acteurs. Document de Travail 185. CIFOR, Bogor. Indonesia

[30] Kengoum F. and TianiA. M. 2013.Politique d'adaptation et d'atténuation au Cameroun: Pistes de synergies. Document occasionnel 96.CIFOR. Bogor. Indonesia.

[31] United Nations Conference on Environment and Development. 1992. Rio Declaration on Environment and Development. available at http://www.un.org/documents/ga/conf151/aconf 15 126-1annex 1.htm

[32] UN-RED. 2013b.Legal Companion to the UN-REDD Programme Guidelines on Free, Prior and Informed Consent (FPIC): International Law and Jurisprudence Affirming the Requirement of FPIC.UN-REDD Programme Secretariat. Geneva. un-redd@un-redd.org

[33] UN-REDD. 2009. UN-REDD Program Operational Guidance: Engagement of Indigenous Peoples \& Other Forest Dependent Communities. UN-REDD Programme Secretariat. Geneva. un-redd@un-redd.org

[34] UN-REDD. 2013a. Guidelines on Free, Prior and Informed Consent. UN-REDD Programme Secretariat. Geneva. un-redd@un-redd.org

[35] Weiss C. H. 1978. "Improving the linkage between social research and public policy". In: Lynn, L.E. (Ed.), Knowledge and Policy: The Uncertain Connection. National Academy of Sciences. Washington DC.

[36] Wyatt S. 2008. First nation, forest land and Aboriginal forestry" in Canada: From exclusion to co-management and beyond. Can. J. For. Res Vol. 38

iThis fieldwork was done within the framework of the project entitled COBAM (Congo Basin forests and climate change: Synergies between adaptation and mitigation), carried out by the Centre for International Forestry Research (CIFOR), in partnership with the University of East Anglia and the Stockholm Environment Institute (SEI), and funded by the African Development Bank.

iiAll the statistical data under this section are collected from the document produced and published at the end of the fieldwork. Cf. Tchatchou B., Chia E. L., Sufo-Kankeu R., Pérez-Terán A. S., Tiani A. M., Sonwa D. J., Kengoum F., Locatelli B., Mekou Y. B., Munoh A. et Kenfack C. E. 2015. Changement climatique dans le Bassin du Congo: Informations et connaissances échangées entre les acteurs. Document de Travail 185. CIFOR, Bogor. Indonesia

iiiln Cameroon, the term "pygmies" is a generic name referring to all the forest indigenous people. They are organized in various ethnic groups and live in all the forest areas of the Country. Normally, in the context of the REDD mechanism, as forest indigenous people, they are supposed to be directly concerned by the FPIC, as they will among other people be the first to be threatened by the implementation of REDD projects.

ivIn the course of my multiple fieldworks in the forest area of Yokadouma in Cameroon, I could really perceive this feeling of fear. Often people complained of not being allowed to enter 'their forests' because there were 'white people' (Referring here to the administration) all over the forest with guns to prevent them. They could simply understand that those people want to protect the trees for Europeans, and the Non timber forest products for the consumption of animals. They were not properly informed of all the logic behind the protection. 